\title{
A Case Report of Hepatic Angiomyolipoma with Negative Premelanosome Marker Immunoprolife with Cirrhosis.
}

\author{
Dr. K. Chandramouleeswari ${ }^{1}$, Dr. P. U. Swathy ${ }^{2}$, Dr. P. Arunalatha ${ }^{3}$, \\ Dr. S. MaryLily ${ }^{4}$ \\ ${ }^{1-}$ Professor, Dept of Pathology, Stanley Medical College \\ ${ }^{2-}$ Postgraduate, dept of pathology, Stanley Medical College \\ 3- Professor, dept of pathology, Stanley Medical College \\ ${ }^{4-}$ Head of Department,dept of pathology, Stanley Medical College
}

\begin{abstract}
Angiomyolipoma (AML) is a relatively rare benign mesenchymal tumor that is frequently found in the kidney and, rarely, in the liver.[1] Hepatic AML is a rare, primarily benign mesenchymal tumor, composed of blood vessels, fat tissue, and smooth muscle cells [2]. Ishak reported the first hepatic AML in 1976 [3] and since then, there have been about 200 cases reported in the literature [8-13] and they have been increasing with improvement in imaging modalities, including ultrasonography (US), computed tomography (CT), magnetic resonance imaging (MRI), and fine-needle aspiration biopsy (FNAB)[4]. The hepatic AML may pose a diagnostic challenge clinically, radiologically, and pathologically because of its wide variation due to the different proportions of the three cell types which make up the tumor. In particular, in a region endemic for hepatocellular carcinoma, the diagnosis of $A M L$ by imaging modality can be difficult and frequently misdiagnosed as hepatocellular carcinoma. The definitive diagnostic study remains the histological examination coupled with immunohistochemical stains. A 44 year old female, a known case of hemangioma liver presented with abdominal distension, loss of appetite and loss of weight. CECT revealed giant liver hemangioma. Enucleation of the tumour done. Histologically, tumour composed of dilated and thick walled arteries, adipose tissue and smooth muscles. Immunohistochemistry with HMB-45 done and found to be negative.Hence this case is presented for its rarity - THE MOST DIAGNOSTIC CRITERION [5] WHICH IS LACKING "HMB -45"
\end{abstract}

Keywords: hepatic angiomyolipoma,HMB-45

\section{Introduction:}

Hepatic angiomyolipoma (HAML) is a rare benign mesenchymal liver tumor first described by Ishak .in 1976 [3]; it belongs to a group of perivascular epithelioid cell tumors called PEComa .[7] The tumor composed of blood vessels, smooth muscle, and adipose cells and due to the variety of predominance of these tissues, its patterns in imaging studies have resulted in a difficulty in diagnosis and misdiagnosis of the tumor as hepatocellular carcinoma (HCC) in some cases . [16,19].Therefore, the preoperative correct diagnosis has been difficult; however, recent advances in imaging diagnosis through a combination of ultrasonography (US), computed tomography (CT), magnetic resonance imaging (MRI), and angiography and specific immunohistochemical analysis of this tumor using human melanoma black-45 antigen (HMB-45) staining have resulted in accurate diagnosis and it is reported that the current accurate preoperative diagnosis was made in $25 \%-52 \%$ of cases.[17,18] The majority of these tumors are believed to be clinically benign during a mean follow-up period of 6.8 years, ,[16] however, an increasing number of cases and aggressive changes including growth in size, recurrence after surgical resection, metastasis, and invasive growth pattern into the parenchyma and along the vessels have been reported.

\section{Case History:}

44 year old female , a known case of hemangioma liver presented with complaints of abdominal distension, loss of appetite, loss of weight and early satiety.

Per abdominal examination revealed massive hepatomegaly.

Investigations revealed elevated Serum bilirubin,serum alkaline phosphatase and Prothrombin time and normal AFP levels.

OGD - Normal.

Contrast enhanced CT revealed 2 large hypodense with peripherally nodular,non-contagious intense enhancement with central non-enhancing areas in right and ;left lobes of liver, largest measuring 22x15.6cms in right lobe - FEATURES SUGGESTIVE OF GIANT HEMANGIOMA OF LIVER WITH ASCITES.

Patient proceeded with Enucleation of the tumour. Intraoperatively, lesion is soft-firm in consistency involving segment $3,4 a$,exophytic in nature compressing stomach and transverse colon. 
Grossly,

Received 2 soft tissue masses largest measuring $17 \times 12.5 \times 8 \mathrm{cms}$ and smallest measuring

$12 \times 11 \times 8 \mathrm{cms}$.External surface- grey brown and studded with tiny nodules.C/s: vaguely circumscribed solid brownish firm mass admixed with yellowish greasy areas and foci showing greenish glistening areas.

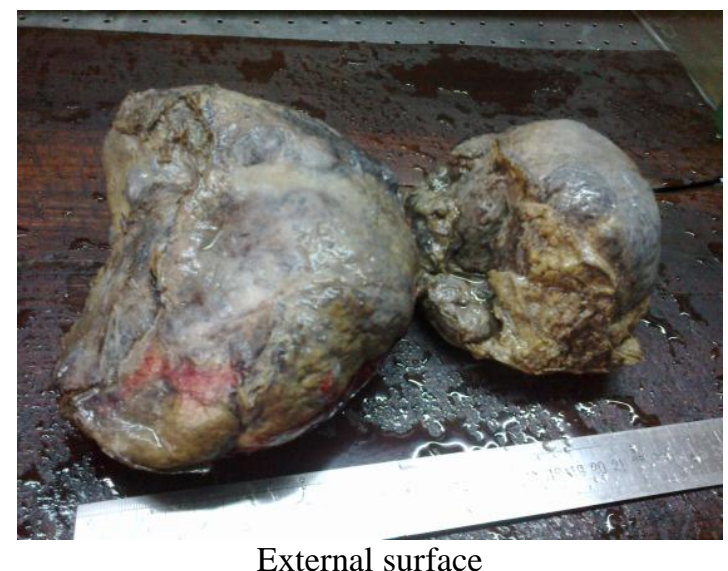

External surface

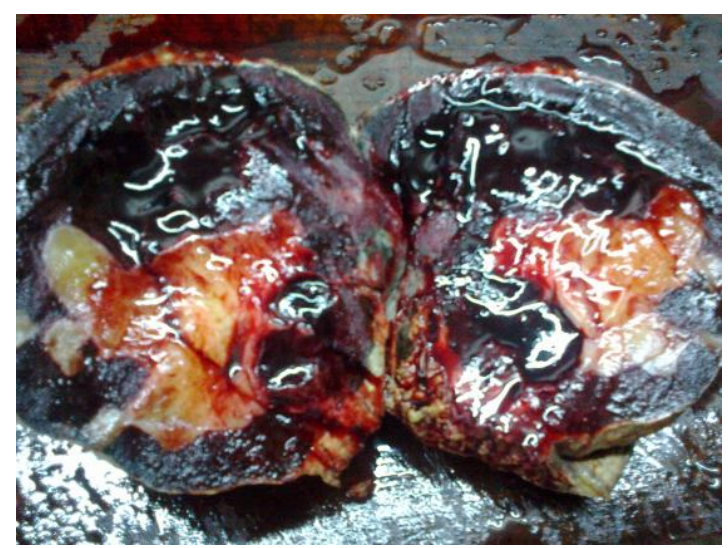

c/s- hemorrhagic \& yellow areas

Histologically,Section shows liver parenchyma with adjoining areas show numerous thick walled vessels lined by endothelial cells,smooth muscle cells and adipose tissue. Adjacent liver tissue shows Cirrhosis.

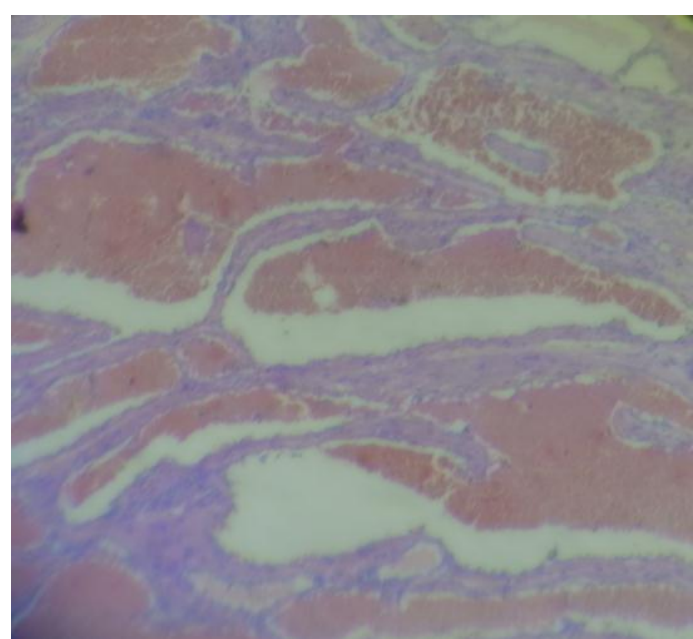

Dilated blood vessels interspersed by smooth muscles 


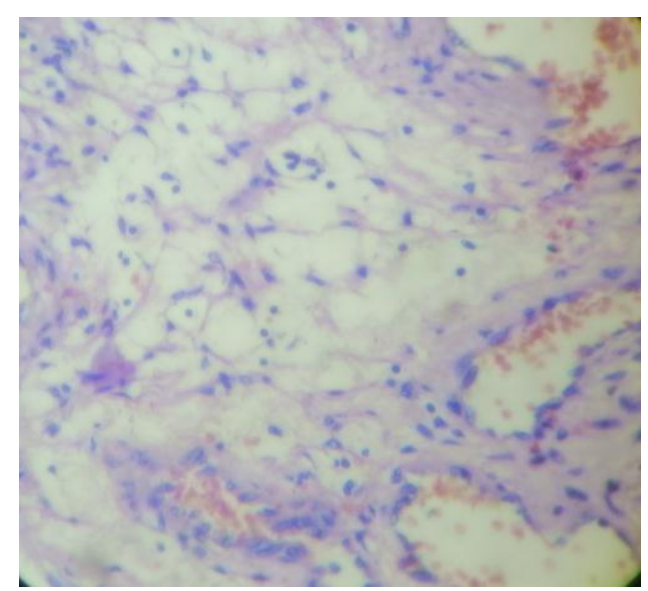

fat cells

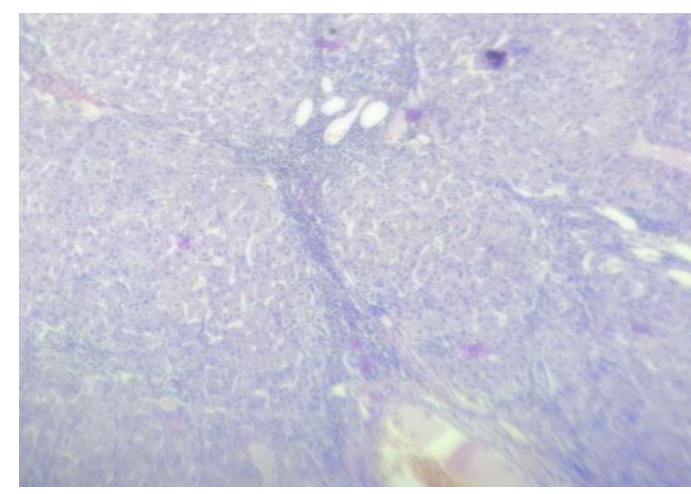

Cirrhosis

Immunohistochemistry with HMB-45, smooth muscles are negative for the marker.

This case is presented for its rarity.

\section{Conclusion:}

\section{Discussion:}

Angiomyolipomas are rare in liver. They most often present at $30-40$ years of age with female preponderance.Around $10 \%$ of tumours occur in the settings of tuberous sclerosis.[22,23]It is considered as a tumour of perivascular epitheloid cells and related tumours in other organs including renal angiomyolipoma,c lear cell sugar tumour and lymphangioleiomyomatosis.[15]Patients present with features of abdominal pain,discomfort ,malaise, fever and anorexia. Rare occurrences have also been reported in many sites including the uterus, retroperitoneum, mediastinum, renal capsule, the hard palate, the nasopharyngeal cavity, the buccal mucosa, fallopian tube, vagina, penis, skin, abdominal wall, stomach, and spinal cord.[22,23]

Grossly, right lobe more often involved.They can grow as large as $36 \mathrm{cms}$ in diameter.Cut surfacevariably coloured depending on the content.Fat is yellowish colour and soft in consistency. Smooth musle is tan white and firm.Hemorrhage may be present.[22,23]

Histologically, composed of varying proportions of smooth muscle like cells,blood vessels and fat often in association with hematopoietic cells.[22,23]

According to the proportion of tissue components, Hepatic angiomyolipoima is classified into lipomatous $(>70 \%)$, myomatous $(<10 \%)$ and angiomatous. [8]

The smooth muscle-like cells are prominent in liver lesions and consists of epitheloid or spindled cells that often surround or "spin off" vessels. The epitheloid cells are round to polygonal with abundant eosinophilic cytoplasm and large nuclei with prominent nucleoli.The cytoplasm may be oncocytic and condensed around the nucleus with a clear zone near the cell membrane giving "spider web " like appearance.

The vascular component is made up of thick walled arterial or venous-like channels admixed with thin walled venous like spaces.

The fatty component is made up of fat cells arranged singly,clusters or sheets. 
Foam cells,Peliotic spaces lacking endothelial lining,dense lymphoid aggregates composed of T and B cells,Hemosiderin ,melanin pigment and variable numbers of hematopoietic elements are also seen.[22,23]

Immunohistochemistry, uniformly express HMB-45,Melan - A,tyrosinase and microophthalmia transcription factor.Spindle cells - smooth muscle actin,desmin positivity and epitheloid cells HMB-45 .Focal S-100 positivity in fat cells and epitheloid cells.[22,23]

HMB stands for Homatrophine methyl bromide. Its target is unique pre melanosome related polypeptide.It stains cytoplasm of tumour cells in melanoma,PEComas, adrenocortical tumour and sex cord tumours of gonads.[21]HMB -45 is the diagnostic criterion for angiomyolipoma.[5] But in our case, since all the components of the tumour are evident morphologically, in spite of HMB-45 being negative, diagnosis of HMB-45 is made.

The lack of PMA expression in our patient' case may be due aberrant antigenic expression.. It is tempting to speculate that specific mutation(s) of the genes expressing premelanosome epitopes are missing in our patient's case,although specific molecular genetic studies have not been performed for confirmation. PMA negative expression has been described even in melanoma cases, and electron microscopic studies need to be performed to confirm the presence of premelanosome structures [14]

It is typically a benign lesion and resection is curative.Rare malignant variants with monotypic epitheloid variant, necrosis,marked pleomorphism and high mitotic activity.[16,20]

\section{References:}

[1]. C. N. Yeh, M. F. Chen, C. F. Hung, T. C. Chen, and T. C. Chao, "Angiomyolipoma of the liver," Journal of Surgical Oncology, vol. 77, no. 3, pp. 195-200, 2001. View at Publisher · View at Google Scholar · View at Scopus

[2]. S. R. Prasad, H. Wang, H. Rosas et al., "Fat-containing lesions of the liver: radiologic-pathologic correlation," Radiographics, vol. 25, no. 2, pp. 321-331, 2005.

[3]. K. G. Ishak, "Mesenchymal tumors of the liver," in Hepatocellular carcinoma, K. Okuda and R. L. Peters, Eds., pp. 247-307, Wiley Medical, New York, NY, USA, 1976.

[4]. T. A. Jiang, Q. Y. Zhao, M. Y. Chen, L. J. Wang, and J. Y. Ao, "Diagnostic analysis of hepatic angiomyolipoma," Hepatobiliary and Pancreatic Diseases International, vol. 4, no. 1, pp. 152-155, 2005.

[5]. Y. De Bruecker, F. Ballaux, S. Allewaert et al., "A solitary hepatic lesion: MRI-pathological correlation of an hepatic angiomyolipoma (2004:4b)," European Radiology, vol. 14, no. 7, pp. 1324-1326, 2004.

[6]. "A Case of Hepatic Angiomyolipoma Which Was Misdiagnosed as Hepatocellular Carcinoma in a Hepatitis B Carrier" Case Reports in Hepatology Volume 2012 (2012), Article ID 606108, 5 pages

[7]. Bonetti F, Pea M, Martignoni G, Doglioni C, Zamboni G, Capelli P, Rimondi P, Andrion A. Clear cell ("sugar") tumor of the lung is a lesion strictly related to angiomyolipoma--the concept of a family of lesions characterized by the presence of the perivascular epithelioid cells (PEC) Pathology. 1994 Jul;26(3):230-6.

[8]. Tsui WM, Colombari R, Portmann BC, Bonetti F, Thung SN, Ferrell LD, Nakanuma Y, Snover DC, Bioulac-Sage P, Dhillon AP. Hepatic angiomyolipoma: a clinicopathologic study of 30 cases and delineation of unusual morphologic variants. Am J Surg Pathol. 1999;23:34-48.

[9]. Goodman ZD, Ishak KG. Angiomyolipomas of the liver. Am J Surg Pathol. 1984;8:745-50.

[10]. Ren N, Qin LX, Tang ZY, Wu ZQ, Fan J. Diagnosis and treatment of hepatic angiomyolipoma in 26 cases. World J Gastroenterol. 2003;9:1856-8.

[11]. Li T, Wang L, Yu HH, Sun HC, Qin LX, Ye QH, Fan J, Tang ZY. Hepatic angiomyolipoma: a retrospective study of 25 cases. Surg Today. 2008;38:529-35.

[12]. Zeng JP, Dong JH, Zhang WZ, Wang J, Pang XP. Hepatic angiomyolipoma: a clinical experience in diagnosis and treatment. Dig Dis Sci. 2010;55:3235-40.

[13]. Chang Z, Zhang JM, Ying JQ, Ge YP. Characteristics and treatment strategy of hepatic angiomyolipoma: a series of 94 patients collected from four institutions. J Gastrointestin Liver Dis. 2011;20:65-9.

[14]. Stone CH, Lee MW, Amin MB, Yaziji H, Gown AM, Ro JY, Têtu B, Paraf F, Zarbo RJ: Renal angiomyolipoma: further immunophenotypic characterization of an expanding morphologic spectrum. Arch Pathol Lab Med 2001, 125:751-758.

[15]. Martignoni G, Pea M, Reghellin D, Zamboni G, Bonetti F. PEComas: the past, the present and the future. Virchows Arch. 2008;2:119-132.15.W. M. S. Tsui, R. Colombari, B. C. Portmann et al., "Hepatic angiomyolipoma: a clinicopathologic study of 30 cases and delineation of unusual morphologic variants," The American Journal of Surgical Pathology, vol. 23, no. 1, pp. 34-48, 1999 .

[16]. A. Nonomura, Y. Enomoto, M. Takeda et al., "Invasive growth of hepatic angiomyolipoma; a hitherto unreported ominous histological feature," Histopathology, vol. 48, no. 7, pp. 831-835, 2006.

[17]. G. H. Ding, Y. Liu, M. C. Wu, et al., "Diagnosis and treatment of hepatic angiomyolipoma," Journal of Surgical Oncology, vol. 103, no. 8, pp. 807-812, 2011.

[18]. Z. G. Chang, J. M. Zhang, J. Q. Ying, and Y. P. Ge, "Characteristics and treatment strategy of hepatic angiomyolipoma: a series of 94 patients collected from four institutions," Journal of Gastrointestinal and Liver Diseases, vol. 20, no. 1, pp. 65-69, 2011.

[19]. . W. M. S. Tsui, R. Colombari, B. C. Portmann et al., "Hepatic angiomyolipoma: a clinicopathologic study of 30 cases and delineation of unusual morphologic variants," The American Journal of Surgical Pathology, vol. 23, no. 1, pp. 34-48, 1999.

[20]. Nguyen TT, et al.: Malignant hepatic angiomyolipoma: report of a case and review of literature. Am J Surg Pathol 2008, 32(5):793-798.

[21]. Gown AM, Vogel AM, Hoak D, Gough F, McNutt MA (1986). "Monoclonal antibodies specific for melanocytic tumors distinguish subpopulations of melanocytes". Am. J. Pathol. 123 (2): 195-203

[22]. Goldblum, surgicalPathology of git,liver,biliary tree and pancreas, $2^{\text {nd }}$ edition,pg 986

[23]. Fletcher, Histopathology of tumours, $4^{\text {th }}$ edition, vol 1-Pg 437-438. 